\title{
Degree of Conversion and Molecular Weight of One Denture Base and Three Reline Resins Submitted to Post-polymerization Treatments
}

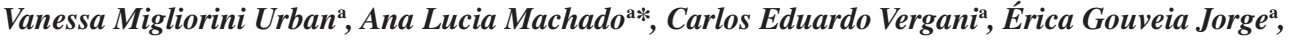 \\ Luís Presley Serejo dos Santos ${ }^{\mathrm{b}}$, Edson Roberto Leite $^{\mathrm{b}}$, Sebastião Vicente Canevarolo ${ }^{\mathrm{c}}$ \\ ${ }^{a}$ Department of Dental Materials and Prosthodontics, Araraquara Dental School, \\ São Paulo State University, Rua Humaitá, 1680, Centro, 14801-903 Araraquara, SP, Brazil \\ ' Interdisciplinary Laboratory of Eletrochemistry and Ceramics, Department of Chemistry, \\ São Carlos Federal University, Rodovia Washington Luís (SP - 310), Km 235, \\ 13565-905 São Carlos, SP, Brazil \\ 'Department of Material Engineering, São Carlos Federal University, \\ Rodovia Washington Luís (SP - 310), Km 235, 13565-905 São Carlos, SP, Brazil
}

Received: March 1, 2007; Revised: May 11, 2007

\begin{abstract}
The effect of post-polymerization treatments (MW-microwave irradiation and WB-water-bath) on the degree of conversion (DC) of three reline resins (Ufi Gel hard-U, Kooliner-K, and Tokuso Rebase Fast-T) and one denture base resin (Lucitone 550-L), submitted to two polymerization cycles (LS-short and LL-long), was evaluated by using FT-Raman spectroscopy $(\mathrm{n}=5)$. The molecular weight $(\bar{M} w)$ of the powder of all materials and of $\mathrm{K}$ polymerized specimens (control; MW; and WB; $n=3$ ) was analyzed using GPC. DC data were analyzed using Kruskal-Wallis test $(\alpha=.05)$. For control specimens, there were no significant differences between U (68\%) and LL (77\%) and among LL, K (81\%), and T (84\%). LS $(92 \%)$ had the highest DC (P < 0.05). Only material K exhibited an increased DC after WB $(\mathrm{P}<0.05)$. All powders had $\bar{M} w$ from $4.0 \times 10^{5}$ to $6.5 \times 10^{5}$ and narrow $\bar{M} w$ distributions (2.1 to 3.6). Polymerization and post-polymerization produced K specimens with $\bar{M} w$ similar to that of $\mathrm{K}$ powder.
\end{abstract}

Keywords: reline resin, degree of conversion, molecular weight, post-polymerization treatment

\section{Introduction}

Due to the alveolar bone resorption, which is an inevitable consequence of tooth loss, removable prostheses require periodic relining to reestablish tissue support for the denture base. Two techniques for relining dentures can be applied, the direct and the indirect ${ }^{1}$. The relining of denture bases directly in the oral cavity using autopolymerizing hard reline acrylic resins is faster than the laboratory-processed reline system. Because of the simplicity of the method and the good fit obtained ${ }^{2}$, the direct relining technique has been used to improve the retention and stability of removable prosthese ${ }^{2}$, thus providing a more equal distribution of the load over the residual ridge.

During the polymerization reaction of the acrylic resins, the conversion of monomers to polymers is incomplete and some unreacted monomers are left in the polymerized materials ${ }^{3}$. Polymerization time and temperature affect the residual monomer content, which is usually higher in autopolymerizing than in heat-polymerizing acrylic resins $^{4,5}$. The residual monomer content is a major factor influencing the properties of the polymers ${ }^{6,7}$. The higher the degree of conversion of double bonds, the greater the mechanical strength of the resins ${ }^{6,7}$. In addition, the unreacted monomer may leach from the polymerized material and irritate the soft tissue ${ }^{8}$.

It has been observed that the amount of residual monomer of acrylic resins can be reduced by post-polymerization treatments such as immersion in hot water ${ }^{9-11}$ or microwave irradiation ${ }^{11-13}$. These treatments have also resulted in improved mechanical properties $^{13,14}$ and biocompatibility of the polymerized materials ${ }^{10}$. While a number of studies have evaluated the degree of conversion of dental composites $^{7,15,16}$, little information is available regarding denture base acrylic resins ${ }^{3,17}$. Moreover, no information could be identified by the authors concerning the degree of conversion of autopolymerizing hard reline resins.

Molecular weight is another important aspect that can influence the performance of a polymer ${ }^{18-20}$. The polymerization of acrylic resins represents a conversion of low molecular weight molecules (monomers) into high molecular weight macromolecules (polymers). Some properties such as fatigue resistance ${ }^{18,21}$, fracture toughness ${ }^{21}$, tensile strength, modulus of elasticity, hardness ${ }^{22}$, impact strength, and glass transition temperature may be affected ${ }^{18}$ when the average molecular weight of narrow molecular weight distribution acrylic is below a limiting value of approximately $10^{520}$. The molecular weight of the prepolymer powder and the particle size distribution are also important factors influencing the doughing time of acrylic resins ${ }^{23,24}$. Some studies have investigated the molecular weight of original powder and polymerized denture base acrylic resins ${ }^{19,23}$. However, there is limited information regarding the molecular weight of hard chair-side reline resins ${ }^{25}$.

The aim of this study is to measure the degree of conversion (DC) of three hard chairside reline resins and one heat-polymerizing denture base acrylic resin, processed using two polymerization cycles. The effect of two post-polymerization treatments on the DC of these materials was also investigated. In addition, the molecular weight of the prepolymer powder of all materials and the molecular weight of a reline resin without crosslinking agent after polymerization and after being submitted to the post-polymerization treatments were analyzed. 


\section{Material and Methods}

The identification codes, brand names, batch numbers, manufacturers, powder/liquid ratios, compositions, and polymerization conditions of the materials used in the present study are listed in Table 1.

\subsection{FT-Raman spectroscopy}

The DC of the materials under investigation was determined by FT-Raman spectroscopy.

Specimens $(n=15)$ of the heat-polymerizing resin Lucitone 550 (L), with dimensions of $10 \times 4 \times 4 \mathrm{~mm}$, were produced by using stainless steel master dies, which were duplicated in silicone rubber to facilitate the removal of the processed specimens from the flask. These silicone molds were then invested in conventional metal dental flasks in Type IV dental stone to create working molds from which the specimens were made. The polymer powder and monomer were mixed following the manufacturer's directions (Table 1) and left covered until the dough stage was reached. The dough formed was packed into the molds, the flasks were closed and left under pressure for 30 minutes. The specimens were then polymerized using one of the two processing cycles recommended by the manufacturer (Table 1). After polymerization, the flasks were allowed to cool for 30 minutes in air, followed by 15 minutes in running water before deflasking. The specimens were then stored in distilled water at $37 \pm 1{ }^{\circ} \mathrm{C}$ for 48 hours $^{26}$.

For the hard chair-side reline resins, specimens $(n=15)$ were fabricated using a stainless steel mold with a breakaway compartment $(10 \times 4 \times 4 \mathrm{~mm})$. The mold was placed on the center of a glass plate, the materials were mixed following the manufacturers' instructions (Table 1) and inserted into the metal mould. A second glass plate was placed over the material, and pressure was applied until polymerization was complete (Table 1).

Specimens of all materials were then divided into three groups of five specimens each. Control group specimens were left untreated $(\mathrm{C})$. MW group specimens were submitted to post-polymerization treatment by placing them in an adjustable microwave oven and irradiating with the following power/time combinations: $550 \mathrm{~W} / 3$ minutes - L (short cycle - LS and long cycle - LL); $550 \mathrm{~W} / 5$ minutes - Kooliner (K); 500 W/5 minutes - Tokuso Rebase Fast (T); and 550 W/4 minutes - Ufi Gel hard (U). These power/time settings were determined in a preliminary study, which evaluated the effect of nine different power/time combinations on the flexural strength of these materials ${ }^{14}$. The power/time setting, which produced the highest flexural strength value for each material, was used in this study. For WB group, the heat-polymerized specimens (LS and LL) were submitted to a post-polymerization treatment by immersion in water bath at $55 \pm 1{ }^{\circ} \mathrm{C}$ for 60 minutes following the recommendation for denture base resins reported by Tsuchiya et al. ${ }^{10}$. Reline resin specimens were immersed in water at $55{ }^{\circ} \mathrm{C}$ for 10 minutes, following a reline material (Duraliner II, Reliance Dental Mfg. Co., Worth, Ill., USA) manufacturer's recommendation to reduce the monomer taste. In addition, the results from a previous study suggested that further polymerization could be achieved by using these MW and WB post-polymerization treatments ${ }^{11}$.

FT-Raman spectra of all specimens were recorded at ambient pressure and temperatures using a Bruker RFS 100/S instrument (Bruker Optics Inc, Billerica, MA, USA) equipped with a broadrange quartz beamsplitter, defocusing optics, and an InGaAs detector. Spectra were obtained with 100 scans at a resolution of $4 \mathrm{~cm}^{-1}$ within a wavelength from 1.000 to $4.000 \mathrm{~cm}^{-1}$ in the transmission mode, under a nitrogen gas purge, using $300 \mathrm{~mW}$ of $\mathrm{Nd}$ :YAG laser power.

The DC (\%) of monomer-to-polymer was calculated by comparison of the absorbance ratio using a standard baseline technique ${ }^{27}$ of the $\mathrm{C}=\mathrm{C}$ peak from the methacrylate group at $1640 \mathrm{~cm}^{-1}$ to that of the unchanging $\mathrm{C}=\mathrm{O}$ peak from the ester group at $1720 \mathrm{~cm}^{-1}$, which was used as a reference peak, before (monomer) and after polymerization (group C), and after the two post-polymerization treatments (groups MW and WB). By taking the ratio between the two absorbances, the fraction of unreacted double bonds could be calculated from the formula:

$\mathrm{DC} \%=\left(1-\frac{[\operatorname{Abs}(\mathrm{C}=\mathrm{C}) / \mathrm{Abs}(\mathrm{C}=\mathrm{O})] \text { polymerized specimen }}{[\mathrm{Abs}(\mathrm{C}=\mathrm{C}) / \mathrm{Abs}(\mathrm{C}=\mathrm{O})] \text { monomer }}\right) \times 100 \%$

The DC values were then analyzed by Kruskal-Wallis test at 95\% level of confidence.

\subsection{Gel permeation chromatography (GPC)}

GPC was used to determined the weight average molecular weight $(\bar{M} w)$, which represents the ratio of the overall weight of the molecules to the weight of the individual molecule, number average molecular weight $(\bar{M} n)$, which is the ratio of the whole molecules present in the

Table 1. Materials evaluated in this study.

\begin{tabular}{|c|c|c|c|c|c|c|c|}
\hline \multirow[t]{2}{*}{ Code } & \multirow[t]{2}{*}{ Brand name } & \multirow[t]{2}{*}{ Batch number } & \multirow[t]{2}{*}{ Manufacturer } & \multirow{2}{*}{$\begin{array}{l}\text { Powder }(\mathrm{P}) / \\
\text { Liquid }(\mathrm{L}) \\
\text { ratio }\left(\mathrm{g} \cdot \mathrm{mL}^{-1}\right) \\
\end{array}$} & \multicolumn{2}{|c|}{ Composition } & \multirow[t]{2}{*}{ Polymerization condition } \\
\hline & & & & & Powder & Liquid & \\
\hline $\mathrm{K}$ & Kooliner & $\begin{array}{l}\text { 080700A (P) } \\
\text { 062900A (L) }\end{array}$ & $\begin{array}{l}\text { Coe Laboratories, } \\
\text { Inc., York, Chicago, Ill., } \\
\text { USA }\end{array}$ & $1.4 / 1.0$ & PEMA & IBMA & 12 minutes at room temperature \\
\hline $\mathrm{T}$ & $\begin{array}{l}\text { Tokuso } \\
\text { Rebase Fast }\end{array}$ & $\begin{array}{l}437(\mathrm{P}) \\
094(\mathrm{~L})\end{array}$ & $\begin{array}{l}\text { Tokuyama Dental Corp., } \\
\text { Tokyo, Japan }\end{array}$ & $2.05 / 1.0$ & PEMA & $\begin{array}{l}\text { MAOP and } \\
\text { 1,6-HDMA }\end{array}$ & 6 minutes at room temperature \\
\hline $\mathrm{U}$ & Ufi Gel hard & $\begin{array}{l}330936(\mathrm{P}) \\
321892(\mathrm{~L})\end{array}$ & $\begin{array}{l}\text { Voco GmbH, Cuxhaven, } \\
\text { Germany }\end{array}$ & $1.76 / 1.0$ & PEMA & 1,6-HDMA & 7 minutes at room temperature \\
\hline LS & $\begin{array}{l}\text { Lucitone } \\
550 \\
\text { (short cycle) }\end{array}$ & $\begin{array}{l}65173(\mathrm{P}) \\
64979(\mathrm{~L})\end{array}$ & $\begin{array}{l}\text { Dentsply International } \\
\text { Inc., York, Pa., USA }\end{array}$ & $2.1 / 1.0$ & PMMA & $\begin{array}{l}\text { MMA and } \\
\text { EGDMA }\end{array}$ & $\begin{array}{l}90 \text { minutes at } 73^{\circ} \mathrm{C} \text { and then } \\
\text { boiling water for } 30 \text { minutes }\end{array}$ \\
\hline LL & $\begin{array}{l}\text { Lucitone } \\
550 \\
\text { (long cycle) }\end{array}$ & $\begin{array}{l}65173(\mathrm{P}) \\
64979(\mathrm{~L})\end{array}$ & $\begin{array}{l}\text { Dentsply International } \\
\text { Inc., York, Pa., USA }\end{array}$ & $2.1 / 1.0$ & PMMA & $\begin{array}{l}\text { MMA and } \\
\text { EGDMA }\end{array}$ & 9 hours at $73{ }^{\circ} \mathrm{C}$ \\
\hline
\end{tabular}

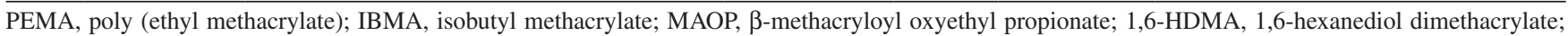
PMMA, poly (methyl methacrylate); MMA, methyl methacrylate; EGDMA, ethylene glycol dimethacrylate. 
mixture to the number of molecules, and polydispersivity $(\bar{M} w / \bar{M} n)$ which expresses molecular weight distribution, of the original powder of all materials. GPC analysis was also used to evaluate the effect of microwave irradiation and water bath post-polymerization treatments on $\bar{M} w, \bar{M} n$ and polydispersivity of polymerized specimens of K reline resin, the only material that does not contain crosslinking agent in its composition (Table 1). During the polymerization reaction, the presence of a crosslinking agent in the liquid monomer leads to the formation of an insoluble crosslinked network (gel) ${ }^{3}$, which impairs the dissolution of samples in tetrahydrofuran ${ }^{19,23}$. Since this dissolution is a pre-requisite for analyzing molecular weight by means of gel permeation chromatography, in the present investigation no attempt was made to examine the molecular weight of the polymerized materials Lucitone 550, Tokuso Rebase Fast and Ufi Gel hard materials, which contain crosslinking agents.

$\mathrm{K}$ specimens $(10 \times 10 \times 1 \mathrm{~mm})$ were fabricated following the manufacturer's instructions and then divided into three groups $(n=3)$. Control group specimens (C) were left untreated. For the MW and WB groups, the specimens were submitted to post-polymerization treatments by microwave irradiation or immersion in hot water, under the same conditions as described for the analysis of degree of conversion of material $\mathrm{K}$.

Polymeric samples (original powder of all materials and specimens of the reline resin $\mathrm{K}$ ) were left for 24 hours to dissolve in HPLC-grade tetrahydrofuran at concentrations of $0.1 \% \mathrm{w} \cdot \mathrm{v}^{-1}$. Polystyrene standard samples $(\mathrm{n}=12)$ of known molecular weight were also dissolved in tetrahydrofuran. Both samples (polymeric and standard) were filtered through a $0.45 \mu \mathrm{m}$ filter and injected into the GPC system (Waters model 410, Mildford, Mass., USA). Three size-exclusion columns (HR-3, HR-4, and HR-5E, Waters, Mildford, Mass., USA) were used and the column temperature was kept at $40{ }^{\circ} \mathrm{C}$. The mobile phase used was tetrahydrofuran at a flow rate of $1 \mathrm{~mL} / \mathrm{min}$. The injection volume was $100 \mu \mathrm{L}$ and a refractometer was used as detector.

Polystyrene standard samples were used to generate a calibration curve of $\log \bar{M} w$ vs. elution volume. Since the volume of eluant is proportional to the log of the molecular weight, a molecular weight distribution was then derived ${ }^{18}$. Polymeric samples were chromatographed under conditions identical to those used for the molecularweight standard determinations.

\section{Results}

The mean DC (\%) and standard deviations for all materials and groups evaluated are given in Table 2 .

For group $\mathrm{C}$, the highest $(\mathrm{P}<0.05) \mathrm{DC}$ mean value was observed for LS specimens. The reline resins $\mathrm{T}$ and $\mathrm{K}$, and the denture base resin processed using the long cycle (LL) did not differ statistically

Table 2. Degree of conversion (\%) expressed as mean values with standard deviations and results of statistical analysis.

\begin{tabular}{llll}
\hline Material & \multicolumn{3}{c}{ Group } \\
\cline { 2 - 4 } & \multicolumn{1}{c}{$\mathrm{C}$} & \multicolumn{1}{c}{ MW } & \multicolumn{1}{c}{ WB } \\
\hline $\mathrm{LS}$ & $92 \pm 2.0 \mathrm{Aa}$ & $89 \pm 4.0 \mathrm{Aa}$ & $92 \pm 1.0 \mathrm{Aa}$ \\
$\mathrm{T}$ & $84 \pm 1.0 \mathrm{Ba}$ & $89 \pm 2.0 \mathrm{Aa}$ & $87 \pm 1.0 \mathrm{Ba}$ \\
$\mathrm{K}$ & $81 \pm 5.0 \mathrm{Ba}$ & $86 \pm 6.0 \mathrm{Aab}$ & $88 \pm 3.0 \mathrm{ABb}$ \\
$\mathrm{LL}$ & $77 \pm 7.0 \mathrm{BCa}$ & $77 \pm 7.0 \mathrm{Ba}$ & $73 \pm 7.0 \mathrm{Ca}$ \\
$\mathrm{U}$ & $68 \pm 6.0 \mathrm{Ca}$ & $74 \pm 1.0 \mathrm{Ba}$ & $71 \pm 6.0 \mathrm{Ca}$ \\
\hline
\end{tabular}

Horizontally, means with identical small letters are not significantly different $(\mathrm{P}>0.05)$; Vertically, means with identical capital letters are not significantly different $(\mathrm{P}>0.05)$. from each other $(\mathrm{P}>0.05)$. In addition, there was no significant difference $(P>0.05)$ between LL and the reline resin $U$. When materials were submitted to microwave irradiation (group MW), no significant differences $(\mathrm{P}>0.05)$ were found in the DC mean values of LS, $\mathrm{T}$ and $\mathrm{K}$ specimens. After water bath post-polymerization treatment (group WB), no significant difference was observed when LS and $\mathrm{K}$ materials were compared, and the DC mean value of $\mathrm{K}$ specimens was not significantly different from that of $\mathrm{T}$ specimens $(\mathrm{P}>0.05)$. After both post-polymerization treatments, the DC mean values of LL and U materials were comparable and significantly lower than the other materials evaluated $(\mathrm{P}<0.05)$. Statistical analysis also revealed that only material $\mathrm{K}$ exhibited a significant increase $(\mathrm{P}<0.05)$ in the DC mean value after water bath post-polymerization treatment. Figure 1 shows Raman spectra between $1600 \mathrm{~cm}^{-1}$ and $1800 \mathrm{~cm}^{-1}$ of representative specimens of Kooliner, with the $\mathrm{C}=\mathrm{C}$, and $\mathrm{C}=\mathrm{O}$ vibrations upper labeled.

The results of the weight average molecular weight $(\bar{M} w)$, number average molecular weight $(\bar{M} n)$, and polydispersivity $(\bar{M} w / \bar{M} n)$ of the original powder of all materials are presented in Table 3. The peak molecular weights were found to be between $4.0 \times 10^{5}$ and $6.5 \times 10^{5}$. All materials investigated in this study demonstrated a distribution of $\bar{M} w / \bar{M} n$ less than 4 (from 2.1 to 3.6). Table 4 shows $\bar{M} w, \bar{M} n$, and $\bar{M} w / \bar{M} n$ mean values of the polymerized $\mathrm{K}$ specimens. It can be seen that, both conditions, polymerization and post-polymerization treatments, did not affect molecular weight values.

The molecular weight distribution curves (MWD) for the original powder of all materials are presented in Figure $2(2 \mathrm{~A}-$ the entire MWD curves; $2 \mathrm{~B}$ - enlargement of the MWD curve in the region of molecular weight lower than $10^{5} ; 2 \mathrm{C}$ - enlargement of the MWD curve in the region of molecular weight higher than $10^{6}$ ). The calculated weight fraction of chains with molecular weight values lower than $10^{5}$ for the original powder of $\mathrm{L}, \mathrm{K}, \mathrm{U}$, and $\mathrm{T}$ were $18,10,6.0$, and $10 \%$, respectively. The calculated weight fraction of chains with molecular weight values higher than $10^{6}$ for the original powder of $\mathrm{L}, \mathrm{K}, \mathrm{U}$, and $\mathrm{T}$ were 7.0, 7.0, 19, and 14\%, respectively. Figure 3 shows the Chain Branching Distribution Function (CBDF) ${ }^{28}$, which quantified the differences between the molecular weight distribution

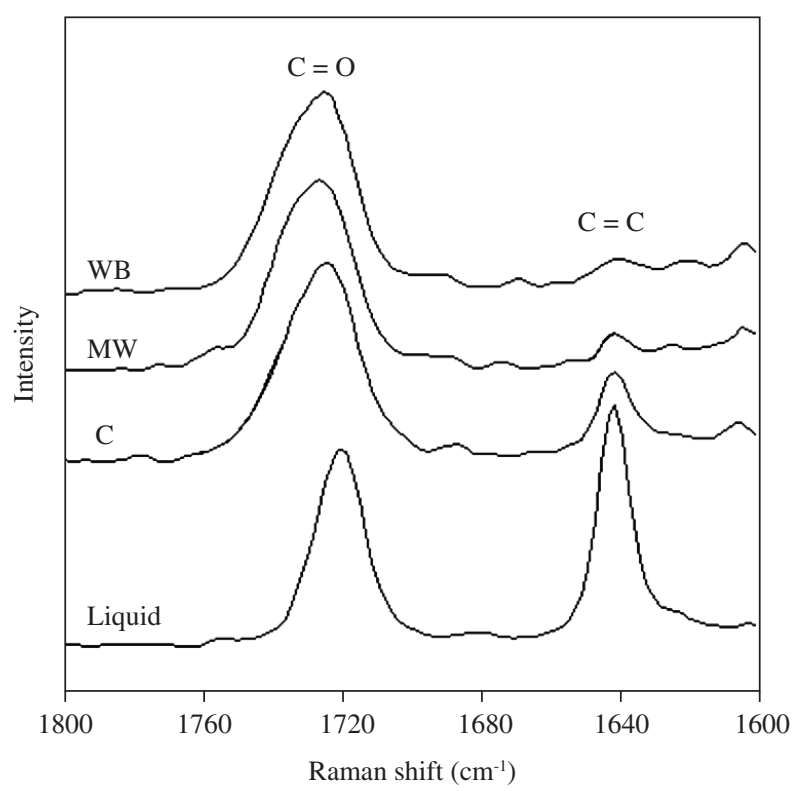

Figure 1. Raman spectra of material K: (liquid) monomer, (C) after polymerization, (MW) after microwave irradiation with $550 \mathrm{~W}$ for 5 minutes, and (WB) after immersion in water at $55^{\circ} \mathrm{C}$ for 10 minutes. 
Table 3. Number average molecular weight $(\bar{M} n)$, weight average molecular weight $(\bar{M} w)$, and polydispersivity $(\bar{M} w / \bar{M} n)$ of the original powder samples for all materials evaluated

\begin{tabular}{cccc}
\hline Material & $\bar{M} w$ & $\bar{M} n$ & $\bar{M} w / \bar{M} n$ \\
\hline $\mathrm{L}$ & $4.0 \times 10^{5}$ & $1.1 \times 10^{5}$ & 3.6 \\
$\mathrm{~T}$ & $5.2 \times 10^{5}$ & $2.2 \times 10^{5}$ & 2.3 \\
$\mathrm{U}$ & $6.5 \times 10^{5}$ & $2.9 \times 10^{5}$ & 2.2 \\
$\mathrm{~K}$ & $4.3 \times 10^{5}$ & $2.1 \times 10^{5}$ & 2.1 \\
\hline
\end{tabular}

Table 4. Number average molecular weight $(\bar{M} \mathrm{n})$, weight average molecular weight $(\bar{M} \mathrm{w})$, and polydispersivity $(\bar{M} \mathrm{w} / \bar{M} n)$ of $\mathrm{K}$ specimens after polymerization (C), and after the two post-polymerization treatments (MW and WB).

\begin{tabular}{lccc}
\hline Group & $\bar{M} w$ & $\bar{M} n$ & $\bar{M} w / \bar{M} n$ \\
\hline C & $4.7 \times 10^{5}$ & $2.1 \times 10^{5}$ & 2.2 \\
MW & $4.7 \times 10^{5}$ & $2.1 \times 10^{5}$ & 2.3 \\
WB & $4.8 \times 10^{5}$ & $2.2 \times 10^{5}$ & 2.1 \\
\hline
\end{tabular}

curves of denture base ( $\mathrm{L}$ ) and reline resin $(\mathrm{K}, \mathrm{U}$, and $\mathrm{T})$ powders. The CBDF curves were calculated using Excel software running a macro. The macro calculates the shift between a point in the reference curve and its correspondent in the other curve ${ }^{29}$.

The molecular weight distribution curves for $\mathrm{K}$ powder, $\mathrm{K}$ after polymerization (C), and $\mathrm{K}$ after post-polymerization treatments (MW and WB) are showed in Figure 4. The calculated weight fraction of chains with molecular weight values lower than $10^{5}$ for $\mathrm{K}$ control, $\mathrm{K}$ after MW, and K after WB were 10, 9.0, and 13\%, respectively. The calculated weight fraction of chains with molecular weight values higher than $10^{6}$ for $\mathrm{K}$ control, $\mathrm{K}$ after $\mathrm{MW}$, and $\mathrm{K}$ after WB were $10,8.0$, and $10 \%$, respectively. Figure 5 shows the Chain Branching Distribution Function (CBDF) ${ }^{28}$, which quantified the differences between the molecular weight distribution curves of $\mathrm{K}$ powder, $\mathrm{K}$ after MW, and K after WB compared with K control.

\section{Discussion}

FT-Raman scattering used in the present investigation is an alternative method that has been widely used to determine the degree of conversion of polymeric materials by measuring the carbon double bonds $(\mathrm{C}=\mathrm{C})$ converted into carbon single bonds $(\mathrm{C}-\mathrm{C})^{15,16}$. The low-power near-infrared laser in the FT-Raman spectrometer makes it possible to analyze colored samples, which can heat in the laser beam, without the loss of sensitivity due to fluorescence of organics ${ }^{30}$. This technique can be applied to normal denture materials with pigments in contrast to the direct infrared method, which can be used only for transparent polymeric materials ${ }^{31}$. Other advantages of FT-Raman scattering include: 1) rapid analysis with a minimum of sample preparation, because the incident radiation can be focused on the sample and the scattered radiation collected with suitable collection optics; 2) the sensitivity of Raman scattering to the highly symmetrical $\mathrm{C}=\mathrm{C}$ vibration of the acrylate resins used in the dentistry ${ }^{16}$.

It has been stated that there is an inverse relationship between the degree of conversion and the residual monomer content, thus the higher the former the lower the latter ${ }^{4-6,32}$. In a previous study ${ }^{11}$, high performance liquid chromatography (HPLC) was conducted to determine the residual monomer content of materials Lucitone 550, Tokuso Rebase Fast, Ufi Gel hard, and Kooliner, under the same conditions used in the present investigation to evaluate their degree of conversion (Table 2). The results from both studies revealed that this inverse relationship was observed for materials Lucitone 550, Ufi Gel hard and Tokuso Rebase Fast. In addition, when these materials

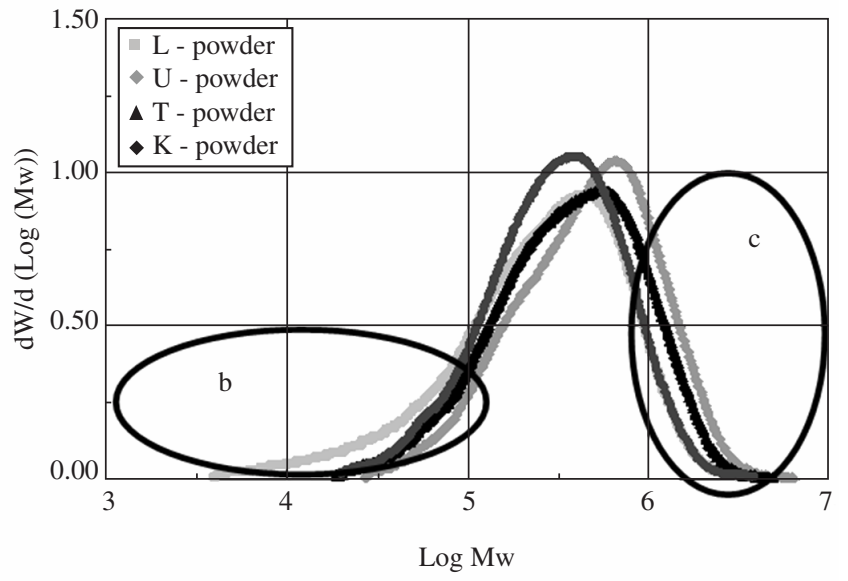

(a)

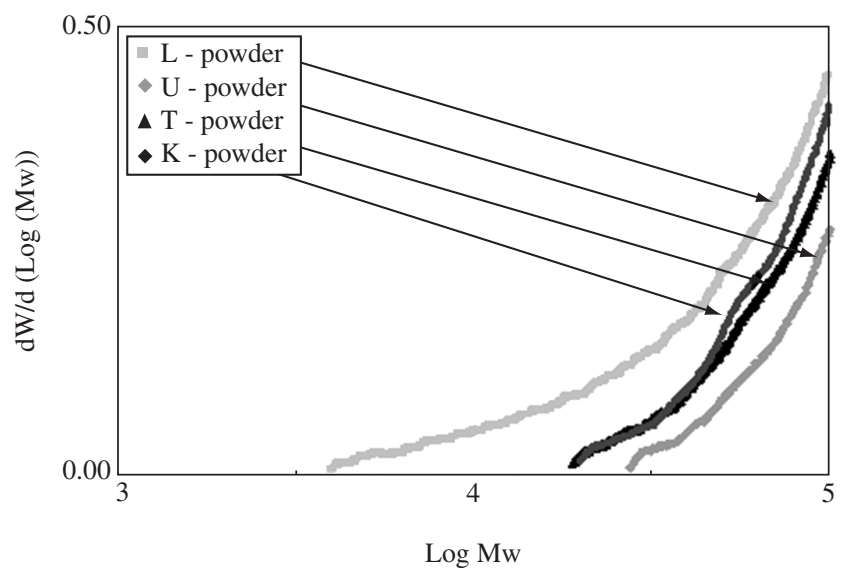

(b)

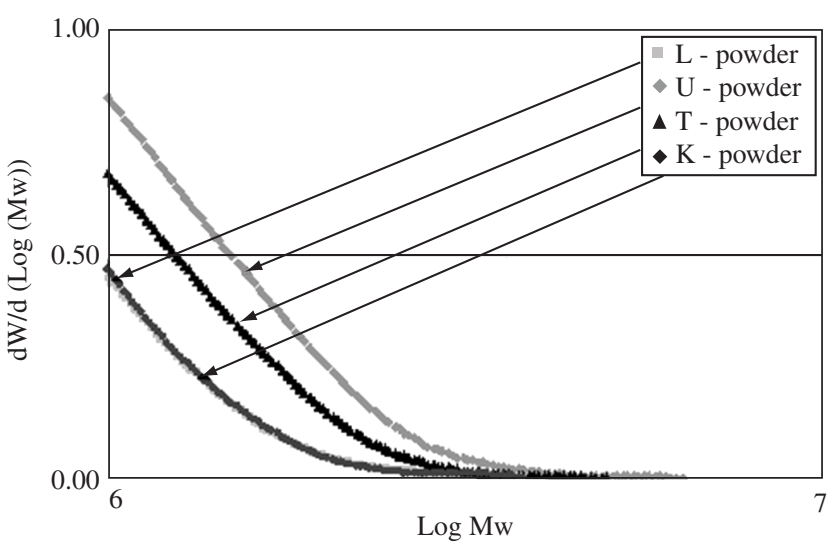

(c)

Figure 2. Molecular weight distribution curves for the original powder of all materials. (a) the entire MWD curves; b) $\bar{M} w / \bar{M} n$ for $\bar{M} w$ lower than $10^{5}$; c) $\bar{M} w / \bar{M} n$ for $\bar{M} w$ higher than $10^{6}$.

were compared, the results followed a similar pattern in both studies. Therefore, the Lucitone 550 specimens polymerized using the short cycle, which included a terminal 30 minutes at $100{ }^{\circ} \mathrm{C}$, showed significantly higher degree of conversion (Table 2) and lower residual monomer levels ${ }^{11}$ than those processed with the long cycle, in all 


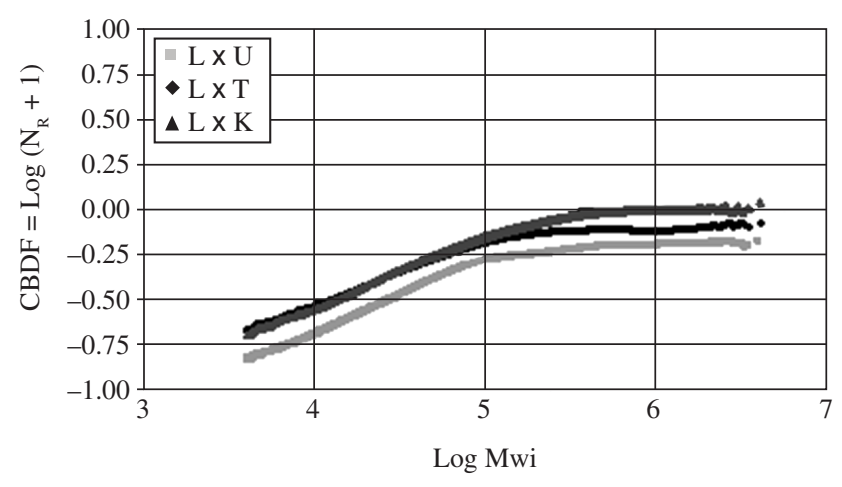

Figure 3. Chain Branching Distribution Function from the comparison of the reference curve (L-powder) with the other curves (K, U, and T-powders).

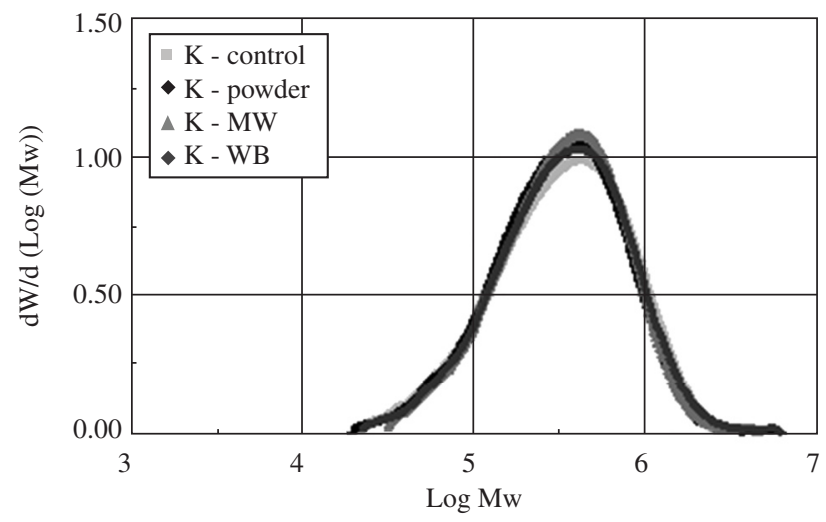

Figure 4. Molecular weight distribution curves for $\mathrm{K}$ powder, $\mathrm{K}$ control, $\mathrm{K}$ after post-polymerization treatments (MW and WB).

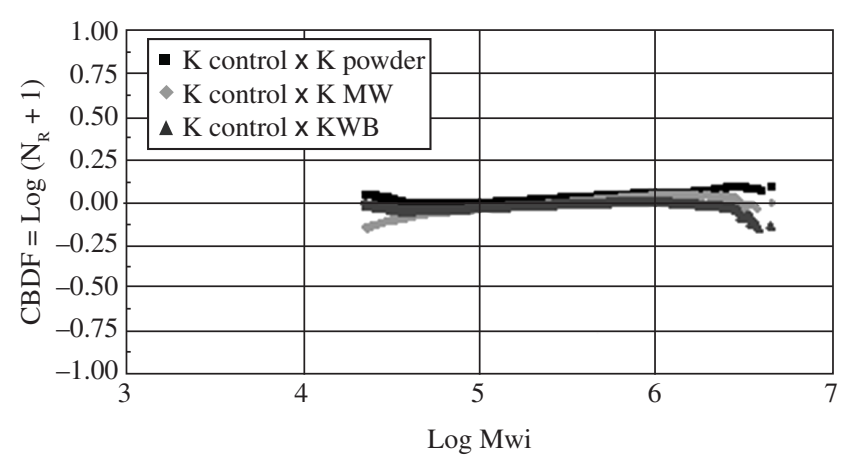

Figure 5. Chain Branching Distribution Function from the comparison of the reference curve (K-control) with the other curves ( $\mathrm{K}$ powder, $\mathrm{K}$ after $\mathrm{MW}$, and $\mathrm{K}$ after WB).

groups evaluated. These results can be attributed to the polymerization temperature used in the long cycle, which is lower than the glass transition temperature $(\mathrm{Tg})$ of the matrix phase of the resin Lucitone $550\left(97.0 \text { to } 100{ }^{\circ} \mathrm{C}\right)^{33}$. As a result, the conversion was limited due to lower molecular chain motions and immobilization of monomer in the glassy polymer ${ }^{3}$.

For the reline resins Ufi Gel hard and Tokuso Rebase Fast, the results from the present investigation also agree well with those previously reported ${ }^{11}$. Ufi Gel hard exhibited higher residual monomer content $^{11}$ and lower degree of conversion compared with Tokuso
Rebase Fast. In addition, in both studies, the values obtained for Ufi Gel hard and Tokuso Rebase Fast reline resins were comparable with those of the denture base resin Lucitone 550, processed using the long and the short cycle, respectively (Table 2$)^{11}$. These findings differ from results of conventional methyl methacrylate-based resins. For these resins, the residual monomer is usually higher in the autopolymerized than in the heat-polymerized materials ${ }^{5,6}$, due to the lower degree of conversion achieved by the use of a chemical activator than that generated by heat-activation. One factor that may have accounted for the favorable results observed for materials Ufi Gel hard and Tokuso Rebase Fast is their composition. These reline resins contain the cross-linking agent 1,6-hexanediol dimethacrylate ${ }^{34}$, whereas Lucitone 550 denture base resin contain the cross-linking agent ethylene glycol dimethacrylate (Table 1). The increased distance between the methacrylate groups of the cross-linking agent 1,6-hexanediol dimethacrylate probably enhanced the reactivity of the second double bond, thus favoring the monomer to polymer conversion ${ }^{33}$. Therefore, despite the fact that the polymerization of Ufi Gel hard and Tokuso Rebase Fast was chemically activated, their degree of conversion and residual monomer level were similar to those of the heat-polymerizing denture base resin Lucitone 550.

Differently from the other materials, a comparison of the results from this study with those of the previous investigation ${ }^{11}$ demonstrated that an indirect relationship between degree of conversion and residual monomer content was not observed for Kooliner reline resin. Table 2 shows that the degree of conversion of Kooliner material did not differ from that of Tokuso Rebase Fast, and was significantly higher than that of Ufi Gel hard, in all groups evaluated. In contrast, the residual monomer level of Kooliner was found to be significantly higher than those of reline resins Ufi Gel hard and Tokuso Rebase Fast $^{11}$. The difference in results between the two studies could be related to the materials composition as well as the analytical methods used in each investigation. Ufi Gel hard and Tokuso Rebase Fast contain dimethacrylate monomer, whereas Kooliner liquid contains the monofunctional monomer isobutyl methacrylate (Table 1). As the polymerization progresses, the network formation decreases the mobility of monomers resulting in unreacted double bonds. Part of these unreacted methacrylate groups remain as monomers that can leach out from the polymerized material. Part of the dimethacrylate monomers react only to one of the double bond, resulting in pendant molecules, which remain bound within the polymer network, and are not free to elute ${ }^{35}$. While Raman spectroscopy used to determine the degree of conversion measures all the unreacted double bonds in the polymer, including pendant groups and extractable species, the HPLC analysis is performed by extraction of the free monomer from the polymerized material ${ }^{11}$. Other investigators also have stated that only a fraction of the unreacted carbon-carbon double bonds in the polymer matrix are present on residual monomer ${ }^{32,35}$. This may help explain why the residual monomer levels of Ufi Gel hard and Tokuso Rebase Fast were lower than that of Kooliner, even though they all had quite similar degree of conversion. Another possible explanation for the differences between this and the previous study could be the fact that the residual monomer was extracted from the whole polymer matrix of each specimen in HPLC analysis. However, Raman spectroscopy is essentially a surface measuring technique, thus spectra reveal the absorption in the actual region representative of the top five microns of the specimens ${ }^{33}$. To validate this hypothesis, however, Raman spectroscopic analysis at different depths of reline resin specimens should be made.

When the effect of post-polymerization treatments on the degree of conversion of the materials evaluated is considered, it was found that only material Kooliner exhibited a significant increase in the degree of conversion after water bath post-polymerization treatment compared 
to control (Table 2 and Figure 1). The reduction in the intensity of the aliphatic $(\mathrm{C}=\mathrm{C})$ peak at $1640 \mathrm{~cm}^{-1}$ in relation to the carbonyl $(\mathrm{C}=\mathrm{O})$ peak at $1720 \mathrm{~cm}^{-1}$ is observed when comparing the spectrum of monomer (liquid) to the control group (C), and the control to the water-bath post polymerization group (WB). These results are also different from those of a previous study ${ }^{11}$, in which both post-polymerization treatments promoted a significant reduction in the residual monomer content of materials Kooliner, Ufi Gel hard and Tokuso Rebase Fast. The denture base resin Lucitone 550 polymerized using the short cycle also showed a significant decrease in the residual monomer after being immersed in hot water. The differences between the two studies may be partially explained by the effects of the post-polymerization treatments on the polymer matrix. During these treatments, mechanisms such as diffusion into water ${ }^{4,9}$, hydrolysis ${ }^{36}$, further polymerization at active sites ${ }^{9,13}$, and monomer volatilization ${ }^{37}$ may reduce significantly the free unreacted monomer, but do not necessarily have an effect on pendant double bonds, which may remain unaltered in the polymer matrix. Therefore, the mechanisms involved in the post-polymerization treatments were more effectively detected when using the HPLC method than by using Raman spectroscopy.

The original powders of all materials were evaluated using gel permeation chromatography (GPC) to determine the weight average molecular weight $(\bar{M} w)$, number average molecular weight $(\bar{M} n)$, and polydispersivity $(\bar{M} w / \bar{M} n)$. GPC analysis was chosen because it is a reliable method of molecular weight determination, enabling molecular weight distributions to be established quickly and accurately ${ }^{38}$, and has been used by several investigators ${ }^{18,19,23,39}$.

It has been shown that the existence of chains with molecular weights of less than $10^{5}$ may have a plasticizer effect, thus weakening the polymer ${ }^{40}$. According to Ruyter and Svendsen ${ }^{33}$, the strength of a polymer increases with increasing molecular weight. However, the strength becomes fairly constant at molecular weights above $6.0 \times 10^{5}$ for polymethyl methacrylate. Figure 2 (A and B) shows that, in comparison to the reline resins, the Lucitone 550 powder contained significantly higher amount of polymer chains having molecular weight lower than $10^{5}$. Large amounts of polymer chains with molecular weight higher than $10^{6}$ was also found for materials Ufi Gel hard and Tokuso Rebase Fast. Figure 3 corroborates this finding, showing that the difference between denture base powder and reline resin powders is more pronounced below $10^{5}$. Among the reline resins tested, the Ufi Gel hard exhibited higher concentration of chains with molecular weight greater than $10^{5}$, when compared with Lucitone 550 . This is demonstrated in Figure 3, where the CBDF curve of material Ufi Gel hard is at a greater distance from the zero line. These results indicated that the polymeric beads of the reline resins are polymerized by the suspension method at a higher degree of polymerization than the denture base material. Despite of this, the $\bar{M} w$ of all original powders, including the Lucitone 550 material, was greater than $10^{5}$ (Table 3), at which chain entanglement occurs ${ }^{29}$, and was in the range where the properties are largely independent of molecular weight. ${ }^{20}$ Hence, it is likely that the molecular weights of the powders will have little effect on the mechanical properties of the polymerized materials.

In addition to the strength, the flow property of a methacrylatebased resin can be regulated by the molecular weight of polymer powders ${ }^{24}$, mainly by the increase in the fraction of molecules with molecular weight higher than $10^{6}$, as observed for materials Ufi Gel hard and Tokuso Rebase Fast. Table 1 shows that the hard chair-side reline resins manufacturers have also added monomers with molecular weight higher than that of methyl methacrylate (100.12), such as isobutyl methacrylate (142.20), and 1,6-hexanediol dimethacrylate (254.33). For reline materials composed of high molecular weight monomers and prepolymers, the working time of the bulk polymerization decreases due to the increase in the material's viscosity. A clinical evaluation of some hard chair-side reline resins demonstrated that the working and setting times were significantly shorter for Tokuso Rebase Fast than for Kooliner ${ }^{2}$. In addition, Kooliner was considered unsatisfactory in $47 \%$ of cases because of the high flow, which make border moulding particularly difficult ${ }^{2}$. Thus, it is likely that the flow characteristics of Ufi Gel hard and Tokuso Rebase Fast mixtures may play a role in producing satisfactory functional impression of the denture-bearing area. However, other studies should evaluate the influence of flow on the impression accuracy and the resulting fit of the relined denture.

It is known that the molecular weight distribution is more important than the attainment of a high average molecular weight, provided that the amount of polymer chains with a molecular weight of less than $10^{5}$ is reduced to a minimum ${ }^{40}$. The chains have the same length and weight when the ratio $\bar{M} w / \bar{M} n$ is equal to 1.0 . However, this is an ideal situation, which is not possible in practice. Polydispersivity up to 5.0 would indicate a narrow distribution and between 5.0 and 20 a medium distribution ${ }^{23}$. In this work, all materials investigated have shown a narrow molecular weight distribution with polydispersivity indices between 2.1 and 3.6 (Table 3). The value for Lucitone 550 resin is in general agreement with those obtained with a conventional crosslinked denture base resin for water-bath polymerization ${ }^{13}$. Moreover, the values obtained for Tokuso Rebase Fast and Kooliner are similar to those obtained by Arima et al. (1.8 and 1.7, respectively). ${ }^{25}$

The results for Kooliner polymerized specimens are not in agreement with Huggett et al. ${ }^{19}$, who demonstrated that the polymerized material generally displayed higher molecular weight values than the original powder component. Tables 3 and 4 present the $\bar{M} w$ values of Kooliner powder and Kooliner after polymerization, respectively. The weight average of Kooliner polymerized was slightly higher than that of Kooliner powder, but the difference is not significant because it is within the systematic error of the method. This observation is also evidenced by the superimposition of all molecular weight distribution curves (Figure 4), and their calculated shift, in terms of the CBDF function, being almost zero (Figure 5). Thus, the molecular weight distribution achieved in bulk polymerization of Kooliner material was shown to be similar to that obtained by the manufacturer during the polymerization of the polymeric powder.

Higher temperatures usually favor faster monomer conversion, since propagation constants and diffusion coefficients increase with temperature. A temperature increase can also affect polymer quality, for example, by affecting the molecular weight distribution or even degrading the polymer chains ${ }^{12}$. However, the molecular weight of Kooliner reline resin was not affected by the heating produced by the post-polymerization treatments (Table 4, Figures 4 and 5).

\section{Conclusion}

Within the parameters of the study design and materials tested, the following conclusions can be draw:

1. The degree of conversion of material Ufi Gel hard was similar to that of Lucitone 550 polymerized using the long cycle, and lower than those of the other materials;

2. In all groups evaluated, the short polymerization cycle produced Lucitone 550 specimens with a significant higher degree of conversion than the long cycle;

3. Water-bath post-polymerization treatment increased the degree of conversion for Kooliner material. The degree of conversion of the other materials was not influenced by both microwave and water-bath post-polymerization treatments;

4. Polymer powder of all materials have weight average molecular weights exceeding $10^{5}$ and narrow molecular weight distributions; and 
5. After polymerization and post-polymerization, the weight average molecular weight values obtained for Kooliner material were similar to that of the original Kooliner powder.

\section{Acknowledgments}

This study was supported by Sao Paulo State Foundation (FAPESP Grant 02/01405-0). The authors would like to thank Dr. Rosa Lucia Simencio and CCDM (Centro de Caracterização e Desenvolvimento de Materiais UFSCar/UNESP) for carrying out the gel permeation chromatography determinations.

\section{References}

1. Dahl JE, Frangou-Polyzois MJ, Polyzois GL. In vitro biocompatibility of denture relining materials. Gerodontology. 2006; 23(1):17-22.

2. Haywood J, Basker RM, Watson CJ, Wood DJ. A comparison of three hard chairside denture reline materials. Part I. Clinical evaluation. European Journal of Prosthodontics and Restorative Dentistry. 2003; 11(4):157-163.

3. Ruyter IE, Oysaed H. Conversion in denture base polymers. Journal of Biomedical Materials Research. 1982; 16(5):741-754.

4. Vallittu PK, Miettinen V, Alakuijala P. Residual monomer content and its release into water from denture base materials. Dental Materials. 1995; 11(6):338-342.

5. Vallittu PK, Ruyter IE, Buykuilmaz S. Effect of polymerization temperature and time on the residual monomer content of denture base polymers. European Journal of Oral Science. 1998; 106(1):588-593.

6. Lee SY, Lai YL, Hsu TS. Influence of polymerization conditions on monomer elution and microhardness of autopolymerized polymethyl methacrylate resin. European Journal of Oral Science. 2002; 110(2):179-183.

7. Sideridou I, Tserki V, Papanastasiou G. Effect of chemical structure on degree of conversion in light-cured dimethacrylate-based dental resins. Biomaterials. 2002; 23(8):1819-1829.

8. Barclay SC, Forsyth A, Felix DH, Watson IB. Case report--hypersensitivity to denture materials. British Dental Journal. 1999; 187(7):350-352.

9. Lamb DJ, Ellis B, Priestley D. The effects of process variables on levels of residual monomer in autopolymerizing dental acrylic resin. Journal of Dentistry. 1983; 11(1):80-88.

10. Tsuchiya H, Hoshino Y, Tajima K, Takagi N. Leaching and cytotoxicity of formaldehyde and methyl methacrylate from acrylic resin denture base materials. Journal of Prosthetic Dentistry. 1994; 71(6):618-624.

11. Urban VM, Machado AL, Oliveira RV, Vergani CE, Pavarina AC, Cass QB. Residual monomer of reline acrylic resins. Effect of water-bath and microwave post-polymerization treatments. Dental Materials. 2007; 23(3):363-368

12. Araújo PHH, Sayer C, Poço JGR, Giudici R. Techniques for reducing residual monomer content in polymers: a review. Polymer Engineering and Science. 2002; 42(7):1442-1468.

13. Blagojevic V, Murphy VM. Microwave polymerization of denture base materials. A comparative study. Journal of Oral Rehabilitation. 1999; 26(10):804-808.

14. Vergani CE, Seo RS, Pavarina AC, dos Santos Nunes Reis JM. Flexural strength of autopolymerizing denture reline resins with microwave postpolymerization treatment. Journal of Prosthetic Dentistry. 2005; 93(6):577-583

15. Emami N, Söderholm KJM, Berglung LA. Effect of light power density variations on bulk curing properties of dental composites. Journal of Dentistry. 2003; 31(3):189-196.

16. Shin WS, Li XF, Schwartz B, Wunder SL, Baran GR. Determination of the degree of cure of dental resins using Raman and FT-Raman spectroscopy. Dental Materials. 1993; 9(5):317-324.

17. Bartoloni JA, Murchison DF, Wofford DT, Sarkar NK. Degree of conversion of denture base materials for varied polymerization techniques. Journal of Oral Rehabilitation. 2000; 27(6):488-493.
18. Beech DR. Molecular weight distribution of denture base acrylic. Journal of Dentistry. 1975; 3(1):19-24.

19. Huggett R, Bates JF, Packham DE. The effect of the curing cycle upon the molecular weight and properties of denture base materials. Dental Materials. 1987; 3(3):107-112.

20. Martin RJ, Johnson JF, Cooper AR. Mechanical properties of polymers: the influence of molecular weight and molecular weight distribution. Journal of Macromolecular Science - Reviews in Macromolecular Chemistry and Physics. 1972; C8(9):57-199.

21. Graham J, Pruitt L, Ries M, Gundiah N. Fracture and fatigue properties of acrylic bone cement. Journal of Arthroplasty. 2000; 15(8):1028-1035.

22. Kusy RP, Katz MJ. Effect of molecular weight on the fracture surface energy of poly(methyl methacrylate) in cleavage. Journal of Materials Science. 1976; 11(7):1475-1486.

23. Harrison A, Magara JB, Huggett R. The effect of variation in powder particle size on the doughing and manipulation times and some mechanical properties of acrylic resin. European Journal of Prosthodontics and Restorative Dentistry. 1995; 3(6):263-268.

24. Mutlu G, Huggett R, Harrison A. Factors that affect the rheologic properties of acrylic resin denture base materials. Journal of Prosthetic Dentistry. 1994; 71(2): 186-191

25. Arima T, Murata H, Hamada T. Analysis of composition and structure of hard autopolymerizing reline resins. Journal of Oral Rehabilitation. 1996; 23(5):346-352.

26. International Organization for Standardization. Specification 1567: denture base polymers. $2^{\text {nd }}$ ed. Switzerland: ISO, 1998.

27. Rueggeberg FA. Determination of resin cure using infrared analysis without an internal standard. Dental Materials. 1994; 10(4):282-286.

28. Pinheiro LA, Chinelatto MA, Canevarolo SV. The role of chain scission and chain branching in high density polyethylene during thermo-mechanical degradation. Polymer Degradation and Stability. 2004; 86(3):445-453.

29. Canevarolo SV. Chain scission distribution function for polypropylene degradation during multiple extrusions. Polymer Degradation and Stability. 2000; 70(1):71-76.

30. Rehman I, Harper EJ, Bonfield W. In situ analysis of the degree of polymerization of bone cement by using FT-Raman spectroscopy. Biomaterials. 1996; 17(16):1615-1619.

31. Austin AT, Basker RM. The level of residual monomer in acrylic denture base materials with particular reference to a modified method of analysis. British Dental Journal. 1980; 149(10):281-286.

32. Ferracane JL. Elution of leachable components from composites. Journal of Oral Rehabilitation. 1994; 21(4):441-452.

33. Ruyter IE, Svendsen SA. Flexural properties of denture base polymers. Journal of Prosthetic Dentistry. 1980; 43(1):95-104.

34. Arima T, Murata H, Hamada T. Properties of highly cross-linked autopolymerizing reline acrylic resin. Journal of Prosthetic Dentistry. 1995; 73(1):55-59.

35. Tuusa SMR, Puska MA, Lassila LVJ, Vallittu PK. Residual monomers released from glass-fibre-reinforced composite photopolymerised in contact with bone and blood. Journal of Materials Science Materials in Medicine. 2005; 16(1):15-20.

36. Koda T, Tsuchiya H, Yamauchi M, Ohtani S, Takagi N, Kawano J. Leachability of denture base acrylic resins in artificial saliva. Dental Materials. 1990; 6(1):13-16.

37. Bagis YH, Rueggeberg FA. The effect of post-cure heating on residual, unreacted monomer in a commercial resin composite. Dental Materials. 2000; 16(4):244-247.

38. Evans JM. Gel permeation chromatography: a guide to data interpretation. Polymer Engineering and Science. 1973; 13(6):401-408.

39. Jones DW, Hall GC, Sutow EJ, Langman MF, Robertson KN. Chemical and molecular weight analyses of prosthodontic soft polymers. Journal of Dental Research. 1991; 70(5):874-879.

40. Anderson JN. Applied dental materials. Blackwell Scientific Publications: Oxford, USA, 1976. 